\title{
Suspected cancer (part 2-adults): reference tables from updated NICE guidance
}

When it was first published, the infographic in this Practice article (BMJ 2015;350:h3044, doi:10.1136/bmj.h3044) contained some inaccuracies, which were corrected on 17 July 2015. These corrections comprised of: we added the link between anal or vulval ulceration and vulval cancer (it previously linked to vaginal cancer in error); we added vulval ulceration to the list of symptoms under gynaecological features; and we added a new category: "Abdominal features (upper gastrointestinal symptoms)." All the symptoms in this new category were previously in the category of "Abdominal features (bowel transit symptoms)," except for the symptom dysphagia, which is a new addition. Thanks to Jodie Moffatt at Cancer Research UK for pointing out these errors.

Cite this as: BMJ 2015;351:h3935

๑ BMJ Publishing Group Ltd 2015 